\title{
Isolation and Characterization of Process Related Impurities in Anastrozole Active Pharmaceutical Ingredient
}

\author{
S. G. Hiriyanna* and K. Basavaiah
}

Department of Chemistry, University of Mysore, Manasagangothri, Mysore-570006, India

\begin{abstract}
Três impurezas no intervalo de 0,08\%-0,12\% por área de pico foram detectadas no ingrediente farmacêutico ativo, anastrazol, por cromatografia líquida de alta eficiência (CLAE) em fase-reversa isocrática. Essas impurezas foram isoladas por prep-CLAE e caracterizadas por CL-EM/EM, CG/EM e dados experimentais de RMN. Com base nos resultados obtidos a partir de diferentes experimentos espectroscópicos, essas impurezas foram caracterizadas como 2,2' - (5- ((4H-1,2,4triazol-4-il)metil)-1,3-fenileno)bis(2-metilpropanonitrila) (Impureza I), 2,2'-(5-metil-1,3fenileno)bis(2-metilpropanonitrila) (Impureza II) e 2,2'-(5-(bromometil)-1,3-fenileno)bis(2metilpropanonitrila) (Impureza III).
\end{abstract}

Three impurities ranging from $0.08 \%-0.12 \%$ by peak area in anastrozole active pharmaceutical ingredient were detected by simple isocratic reverse-phase high performance liquid chromatography (HPLC). These impurities were isolated by prep-HPLC and were characterized by LC-MS/ MS, GCMS and NMR experimental data. Based on the results obtained from different spectroscopic experiments, these impurities have been characterized as 2,2'-(5-((4H-1,2,4-triazol-4-yl) methyl)-1,3-phenylene)bis(2-methylpropanenitrile) (Impurity I), 2,2'-(5-methyl-1,3-phenylene) bis(2-methylpropanenitrile) (Impurity II) and 2,2'-(5-(bromomethyl)-1,3-phenylene)bis(2-methylpropanenitrile) (Impurity III).

Keywords: anastrozole, prep-HPLC, impurities, Mass Spectrometry, NMR, identification and characterization

\section{Introduction}

Anastrozole, chemically known as 2,2'-(5-((1H-1, 2,4-triazol-1-yl)methyl)-1,3-phenylene)bis(2-methylpropanenitrile), is approved by the FDA for the treatment of late-stage breast cancer in post-menopausal women. ${ }^{1-5} \mathrm{It}$ is a potent aromatase inhibitor, ${ }^{2}$ which prevents androgen conversion to estrogens. Breast carcinoma has become a major health problem over the past 50 years, affecting as many as one in eight women. ${ }^{4}$ Although there have been substantial developments in its treatment, approximately $25 \%$ of women with breast carcinoma will eventually die from the disease. ${ }^{6}$

\footnotetext{
*e-mail: hiriyannag@gmail.com
}

Impurities in active pharmaceutical ingredient (API) are highly undesirable and in some cases can prove to be harmful to the patient. The ICHQ7 is a guidance for API manufacturers, mentions that impurities be maintained below set limits. Thus it is pertinent to identify and characterize the impurities in API in order to develop suitable process where in their levels can be kept within permissible limits. The impurity profile study should be carried out for any bulk drug to identify and characterize all the unknown impurities that are present at a level of above $0.05 \%$. A comprehensive study has been undertaken to isolate and characterize these impurities by spectroscopic techniques. This research article describes the separation, identification, isolation and characterization of three impurities that are present in the range of $0.08 \%-0.12 \%$ by peak area in the bulk drug of anastrozole. 


\section{Experimental}

\section{Samples and chemicals}

The anastrozole bulk drug sample was received from Cipla Ltd, India. HPLC grade acetonitrile was obtained from Merck Co., Mumbai, India. A. R. grade ammonium acetate was obtained from Merck Co., Mumbai, India. Ultra pure water was collected from Elix Millipore water purification system. HPLC grade dichloromethane used for liquid / liquid extraction was purchased from Spectrochem, Mumbai, India. Nitrogen, Hydrogen and Zero Air used were of ultra pure grade $(99.999 \%)$.

\section{High Performance Liquid Chromatography (analytical)}

An Waters HPLC system equipped with Alliances 2695 series low pressure quaternary gradient pump along with photo diode array detector and auto sampler has been used for the analysis of samples. The data was collected and processed using Waters "Empower 2" software. An Inertsil ODS-3V (250* 4.6 mm, 5-Micron, GL Sciences, Japan) column was employed for the separation of impurities from anastrozole. The column eluent was monitored at $210 \mathrm{~nm}$. A simple isocratic reverse-phase HPLC method was optimized for the separation of impurities from anastrozole active pharmaceutical ingredient where the mobile phase ratio was a mixture of $2 \mathrm{mmol} \mathrm{L}^{-1}$ ammonium acetate and acetonitrile in a ratio of 50:50, v/v. Chromatography was performed at room temperature using at a flow rate of $1.0 \mathrm{~mL} \mathrm{~min}{ }^{-1}$. The chromatographic run time was $40 \mathrm{~min}$.

\section{High Performance Liquid Chromatography (preparative)}

An Agilent prep-HPLC system equipped with 1200 series pump, photo diode array detector, auto sampler fitted with $5000 \mu \mathrm{L}$ loop and 1200 series preparative fraction collector was used. The data was collected and processed using Agilent "Chemstation" software. An inertsil C18 column (250 × $20 \mathrm{~mm}$, 5-Micron,) was employed for loading the sample. An analytical method was developed in isocratic mode separately to resolve these impurities, followed by scaling up the same method for prep-HPLC to collect the required impurity fractions. The mobile phase consisted of $2 \mathrm{mmol} \mathrm{L}^{-1}$ ammonium acetate and acetonitrile in the ratio of 50:50, (v/v). The flow rate was set at $25 \mathrm{~mL} \mathrm{~min}^{-1}$. Detection was carried out at $210 \mathrm{~nm}$. Approximately $100 \mathrm{mg} \mathrm{mL}^{-1}$ of sample was prepared using acetonitrile and water in the ratio of 70:30, v/v as diluent to load on to the column.

\section{Mass spectrometry (GC-MS)}

Mass spectra were run on Agilent 5973 series using ionization electron beam energy of $70 \mathrm{eV}$. The sample was introduced into the source by connecting the capillary GC column. Initial temperature of oven was set at $100{ }^{\circ} \mathrm{C}$ for 3 min followed by increasing temperature to $300{ }^{\circ} \mathrm{C}$ at the rate of $30^{\circ} \mathrm{C} \mathrm{min}{ }^{-1}$ and held for $20 \mathrm{~min}$. The source manifold and quadrupole temperatures were maintained at $230{ }^{\circ} \mathrm{C}$ and $150{ }^{\circ} \mathrm{C}$ respectively.

\section{Mass Spectrometry (LC-MS/MS)}

LC-MS/MS analysis has been performed on API 2000, Mass Spectrometer (Applied Biosystems). The analysis was performed in positive ionization mode with turbo ion spray interface. The parameters for ion source voltage $\mathrm{IS}=5500 \mathrm{~V}$, declustering potential, $\mathrm{DP}=70 \mathrm{~V}$, focusing potential, $\mathrm{FP}=400 \mathrm{~V}$, entrance potential, $\mathrm{EP}=10 \mathrm{~V}$ were set with nebuliser gas as air at a pressure of 40 psi and curtain gas as nitrogen at a pressure of 25 psi. An Inertsil ODS-3V (250* 4.6 mm, 5-Micron, GL Sciences, Japan) column was used for the separation. The mobile phase is a mixture of $2 \mathrm{mmol} \mathrm{L}^{-1}$ ammonium acetate and acetonitrile in a ratio of 50:50(v/v). The analysis was performed at a flow rate of $1.0 \mathrm{~mL} \mathrm{~min}^{-1}$ with splitting.

\section{NMR spectroscopy}

The ${ }^{1} \mathrm{H},{ }^{13} \mathrm{C}$ NMR and DEPT experiments were carried out at precessional frequencies of $399.939 \mathrm{MHz}$ and 100.574 $\mathrm{MHz}$ respectively, in $\mathrm{CDCl}_{3}$ at $25^{\circ} \mathrm{C}$ temperature on a Varian-400 FT NMR spectrometer. ${ }^{1} \mathrm{H}$ and ${ }^{13} \mathrm{C}$ chemical shifts are reported on the $\delta$ scale in ppm, relative to tetra methyl silane (TMS) $\delta 0.00$ and $\mathrm{CDCl}_{3}$ at $77.0 \mathrm{ppm}$ in ${ }^{13} \mathrm{C}$ NMR respectively.

\section{Results and Discussion}

\section{Detection of impurities by HPLC}

Typical analytical HPLC chromatogram of anastrozole bulk drug and its impurities obtained by using the HPLC method discussed under the heading 'High Performance Liquid Chromatography (analytical)' is shown in Figure 1. The targeted impurities under study are marked as Impurity I, II and III eluted at retention times of about $4.5 \mathrm{~min}, 23.7 \mathrm{~min}$ and $26.0 \mathrm{~min}$ respectively, while anastrozole eluted at about $6.5 \mathrm{~min}$.

\section{Isolation of the impurities by prep-HPLC}

A simple reverse phase chromatographic system, discussed under the heading 'High Performance Liquid Chromatography (preparative)' was used for isolating the impurities. In this 


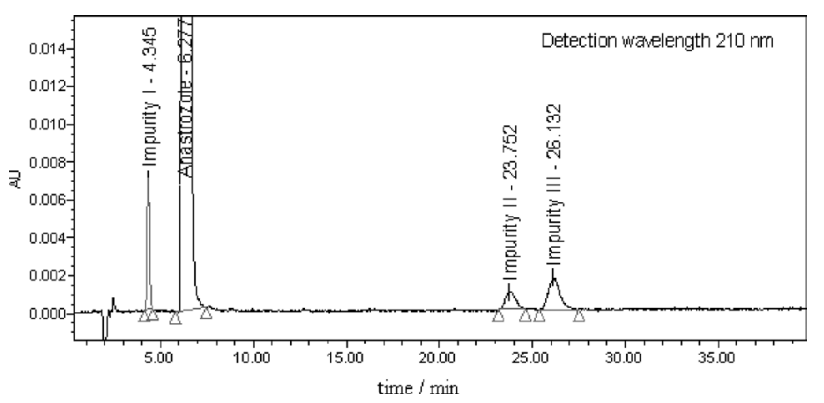

Figure 1. A typical HPLC chromatogram of anastrozole bulk drug.

chromatographic system, anastrozole eluted at about $7.6 \mathrm{~min}$ whereas the impurity I eluted at about $5.4 \mathrm{~min}$, impurity II and impurity III eluted at about $24 \mathrm{~min}$ and $27 \mathrm{~min}$ respectively. The impurity I fraction was collected between $5.2 \mathrm{~min}$ and $5.8 \mathrm{~min}$, impurity II fraction was collected between $23.6 \mathrm{~min}$ and $25.2 \mathrm{~min}$ and impurity III fraction was collected between $26.5 \mathrm{~min}$ and $28.3 \mathrm{~min}$. The impurity fractions were concentrated by evaporating acetonitrile portion at room temperature under high vacuum on a Buchii Rotavapour Model R124. The concentrated aqueous layer containing individual impurity was extracted into methylene chloride. These fractions were concentrated by evaporating methylene chloride layer to get the residue at room temperature under high vacuum on a Rotavapour. Purity of these impurities was tested in analytical mode and was found to be $99.1 \%, 97.9 \%$ and $96.3 \%$ (Figure 2) before carrying out spectroscopic experiments.

\section{LC-MS/MS analysis}

LC-MS/MS analysis of anastrozole bulk drug sample and impurity I was performed using the chromatographic system as
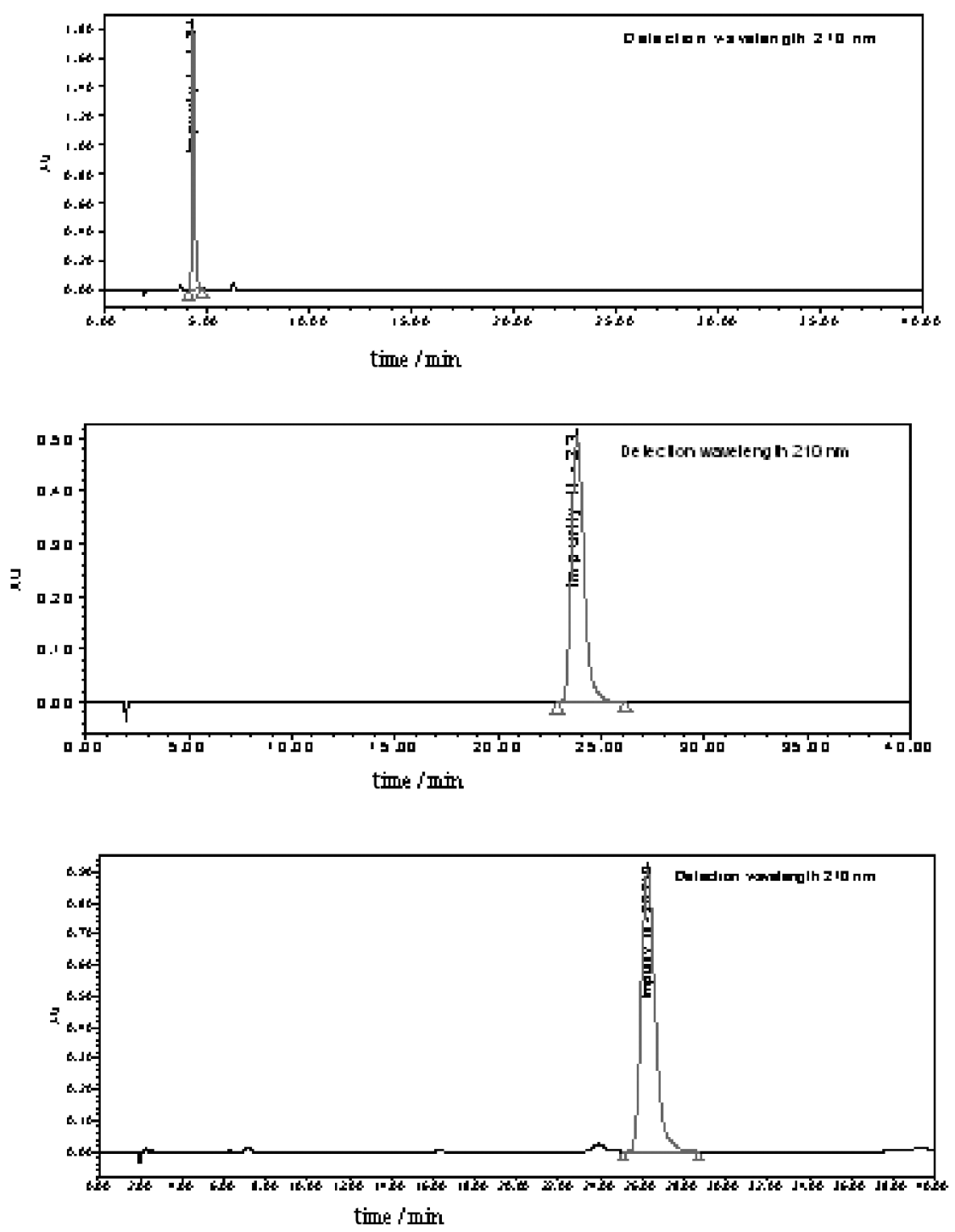

Figure 2. HPLC chromatograms of isolated impurities I, II and III. 


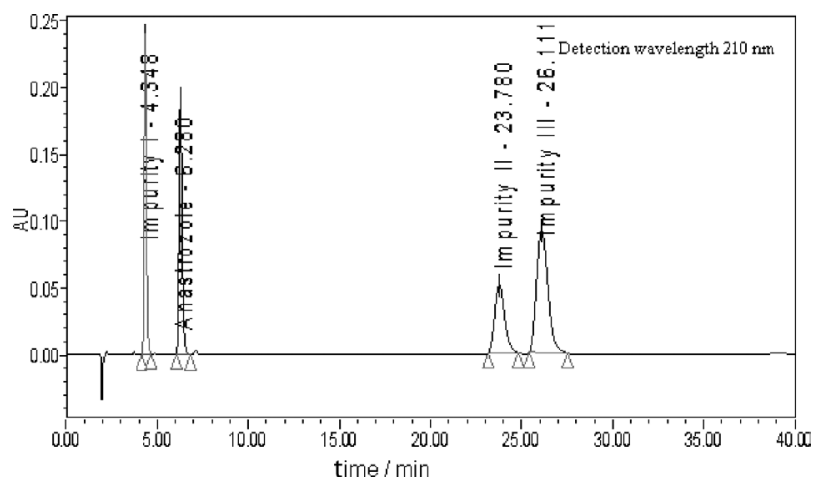

Figure 3. A HPLC chromatogram of anastrozole bulk drug spiked with impurities I, II, and III.

described under the heading 'Mass spectrometry (LC-MS/MS)'. Results of LC-MS/MS analysis revealed that impurity I exhibited molecular ion at $m / z(M+1) 294$ amu (Table 1) and fragmentation pattern is very similar to that of anastrozole (Figure 7). Based on this fact it was assumed that the first impurity was similar to that of anastrozole which might be a positional isomer. Impurity I and impurity II were analyzed comfortably by GC-MS.

\section{GC-MS analysis}

GC-MS analysis of impurity II and impurity III was performed using the method as described in under the heading 'Mass spectrometry (GC-MS)'. Electronic impact ionization of impurity II exhibited molecular ion at $\mathrm{m} / z, 226$ $\mathrm{M}+$ ) amu where the Bromine abundance was found to be absent. Fragmentation pattern also matched in GC-MS for this impurity. The impurity III exhibited molecular ion at $\mathrm{m} / \mathrm{z}$ 304(M+) amu where bromine isotopic abundance was found to be present (Table 2).

\section{Structural elucidation of impurity I}

The spectral data of this impurity was compared with that of anastrozole spectral data. LC-MS/MS analysis exhibited molecular ion for this impurity at $m / z$ 294(M+1). Fragmentation pattern of anastrozole and impurity were also exactly matching. The ${ }^{1} \mathrm{H}$ NMR spectrum of anastrozole exhibited two separate signals for the protons on the triazole ring which indicated that these two protons on the triazole ring were chemically non-equivalent. It was quite interesting to note that the ${ }^{1} \mathrm{H}$ NMR spectrum of this impurity exhibited a single signal integrating for two protons attached to the triazole ring. The ${ }^{1} \mathrm{H}$ NMR spectrum is shown in Figure 6. This observation indicated that the two protons attached to triazole ring were in chemically equivalent environment. ${ }^{13} \mathrm{C}$ NMR and DEPT-NMR experiments were also performed for this impurity. The two carbon atoms in the triazole ring were resonated at the same frequency as compared to that

Table 1. Major mass fragments of Anastrozole and impurities

\begin{tabular}{cc}
\hline Compound & Major fragments / amu \\
\hline Anastrozole & $294.3(\mathrm{M}+1), 225.3,210.3,198.3,195.3,130.2$ \\
Impurity I (m/z: $294 \mathrm{amu})$ & $294.2(\mathrm{M}+1), 225.3,210.0,198.2,195.2,130.4$ \\
Impurity II (m/z: $226 \mathrm{amu})$ & $226(\mathrm{M}+), 211,184,117$ \\
Impurity III (m/z: $306 \mathrm{amu})$ & $304(\mathrm{M}+), 225,210,142,115$ \\
\hline
\end{tabular}

Table 2. ${ }^{1} \mathrm{H}$ NMR, DEPT and ${ }^{13} \mathrm{C}$ NMR assignments for Anastrozole and impurities

\begin{tabular}{|c|c|c|c|c|c|c|c|c|c|c|c|c|c|}
\hline \multirow[t]{2}{*}{ Position } & \multicolumn{3}{|c|}{ Anastrozole } & \multirow[t]{2}{*}{ Position } & \multicolumn{3}{|c|}{ Impurity I } & \multicolumn{3}{|c|}{ Impurity II } & \multicolumn{3}{|c|}{ Impurity III } \\
\hline & ${ }^{1} \mathrm{H} / \mathrm{ppm}$ & ${ }^{13} \mathrm{C}$ & DEPT & & ${ }^{1} \mathrm{H} / \mathrm{ppm}$ & ${ }^{13} \mathrm{C}$ & DEPT & ${ }^{1} \mathrm{H} / \mathrm{ppm}$ & ${ }^{13} \mathrm{C}$ & DEPT & ${ }^{1} \mathrm{H} / \mathrm{ppm}$ & ${ }^{13} \mathrm{C}$ & DEPT \\
\hline 1 & - & 143.48 & - & 1 & - & 144.32 & - & - & 142.48 & - & - & 143.31 & - \\
\hline 2,6 & $2 \mathrm{H} / 7.3$ & 124.49 & 124.5 & 2,6 & $2 \mathrm{H} / 7.28$ & 124.27 & 124.26 & $2 \mathrm{H} / 7.26$ & 125.71 & 125.71 & $2 \mathrm{H} / 7.48$ & 125.63 & 125.63 \\
\hline 3,5 & - & 124.01 & - & 3,5 & - & 123.8 & - & - & 124.53 & - & - & 124.1 & - \\
\hline 4 & $1 \mathrm{H} / 7.5$ & 122.26 & 122.26 & 4 & $1 \mathrm{H} / 7.57$ & 122.75 & 122.75 & $1 \mathrm{H} / 7.34$ & 118.89 & 118.89 & $1 \mathrm{H} / 7.50$ & 122.06 & 122.06 \\
\hline 7,11 & - & 37.39 & - & 7,11 & - & 37.54 & - & - & 37.41 & - & - & 37.48 & - \\
\hline 8,12 & - & 136.97 & - & 8,12 & - & 136.36 & - & - & 139.76 & - & - & 139.78 & - \\
\hline $9,10,13,14$ & $12 \mathrm{H} / 1.65$ & 29.15 & 29.15 & $9,10,13,14$ & $12 \mathrm{H} / 1.75$ & 29.25 & 29.26 & $12 \mathrm{H} / 1.74$ & 29.34 & 29.34 & $12 \mathrm{H} / 1.75$ & 29.35 & 29.35 \\
\hline 15 & $2 \mathrm{H} / 5.36$ & 53.11 & 53.1 & 15 & $2 \mathrm{H} / 5.36$ & 49.02 & 49.02 & $3 \mathrm{H} / 2.41$ & 21.8 & 21.8 & $2 \mathrm{H} / 4.51$ & 32.5 & 32.51 \\
\hline 17 & $1 \mathrm{H} / 7.95$ & 143.64 & 143.64 & 17,20 & $2 \mathrm{H} / 8.24$ & 142.93 & 142.93 & & & & & & \\
\hline 19 & $1 \mathrm{H} / 8.13$ & 152.53 & 152.53 & & & & & & & & & & \\
\hline
\end{tabular}

Note: For numbering refer Figure 5. 


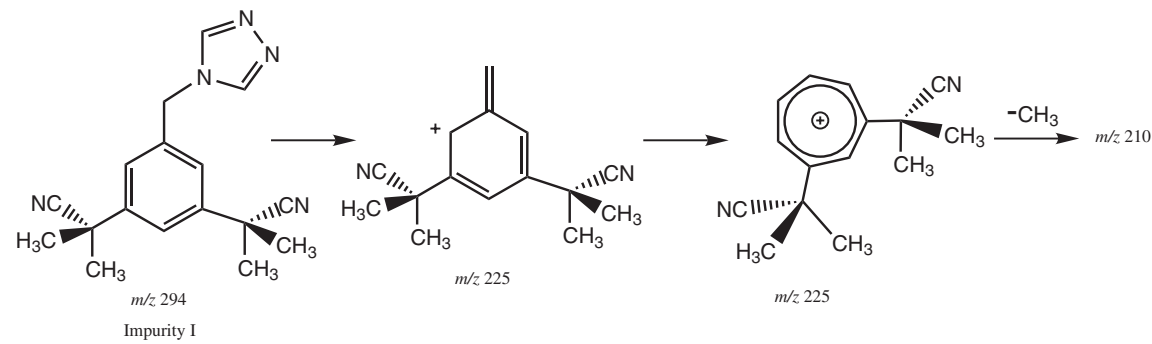<smiles>CC(C)=NC(C)(C)c1cc(C)cc(C(C)(C)N)c1</smiles>

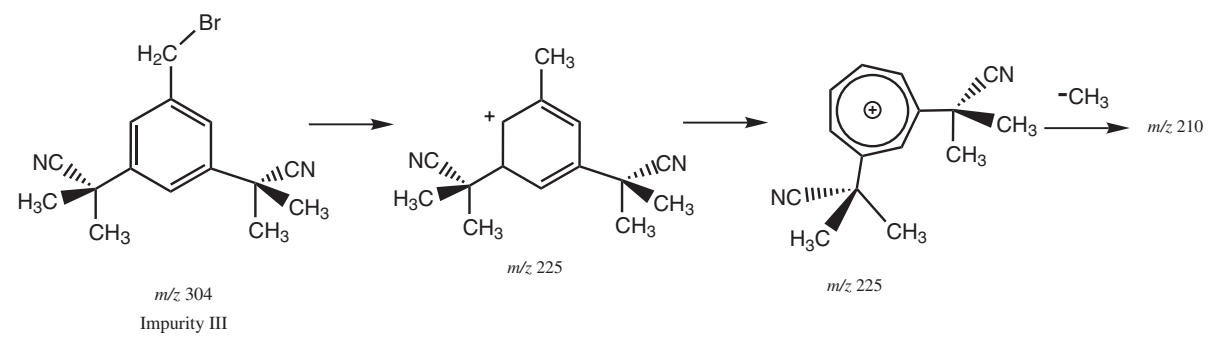

Figure 4. Proposed fragmentation pathways of impurities I, II, and III.

of anastrozole. This observation further confirmed that two carbon atoms of this impurity in the triazole ring were chemically equivalent (see Table 2). Based on these spectral results, it was confirmed that the impurity having the molecular formula $\mathrm{C}_{17} \mathrm{H}_{19} \mathrm{~N}_{5}$ and the same was characterized as 2,2'-(5-((4H-1,2,4-triazol-4-yl)methyl)1,3-phenylene)bis(2-methylpropanenitrile). Chemical structures of anastrozole and impurities are shown in Figure 5. Fragmentation pathways for impurities are shown in Figure 4. Major fragments obtained in LC-MS/MS analysis for anastrozole and its impurities are given in Table 1.

\section{Structural elucidation of impurity II}

The mass spectrum of impurity II exhibited a molecular ion at $(\mathrm{M}+) 226$ atomic mass unit (amu) (Figure 8) which was $67 \mathrm{amu}$ less than that of anastrozole. The even molecular ion of impurity II indicates the possible presence of even number of nitrogen atoms. The ${ }^{1} \mathrm{H}$ NMR spectrum of impurity II showed signal at $\delta 2.41 \mathrm{ppm}$ due to - $\mathrm{CH} 3-$ proton, which was not observed in the ${ }^{1} \mathrm{H}$ NMR spectrum of anastrazole. This observation was supported by the appearance of signals at $\delta 7.95$ and $\delta 8.13 \mathrm{ppm}$ due to<smiles>CC(C)(C)c1cc(Cn2cnnn2)cc(C(C)(C)N)c1</smiles>

Anastrozole<smiles>Cc1cc(C(C)(C)N)cc(C(C)(C)N)c1</smiles>

Impurity II<smiles>CC(C)(C)c1cc(Cn2cnnc2)cc(C(C)(C)N)c1</smiles>

Impurity I<smiles>CC(C)(C)c1cc(C=O)cc(C(C)(C)C)c1</smiles>

Impurity III
Figure 5. Chemical structures of anastrozole and its impurities.

the triazole ring proton in the anastrozole, which was not observed in the ${ }^{1} \mathrm{H}$ NMR spectrum of impurity II. Further the ${ }^{1} \mathrm{H}$ NMR spectrum displayed signal at $\delta 5.36 \mathrm{ppm}$ due to methylene proton in the anastrazole, which was absent in the ${ }^{1} \mathrm{H} N M R$ spectrum of impurity II. On the other hand ${ }^{13} \mathrm{C}$ NMR 

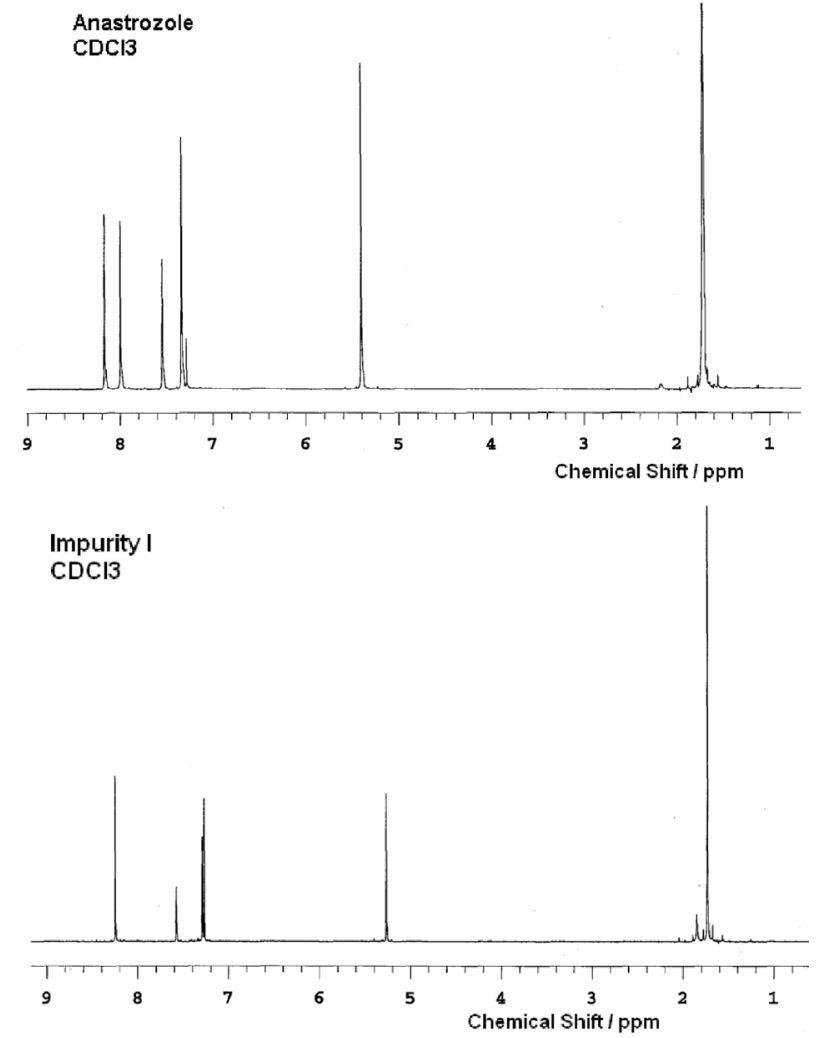

Figure 6. ${ }^{1} \mathrm{H}$ NMR spectrum of anastrozole and impurity I. spectrum of impurity II shows signal at $\delta 21.80 \mathrm{ppm}$ due to methyl group which was not observed in the ${ }^{13} \mathrm{C}$ NMR spectrum of anastrazole. In addition to this observation DEPT spectrum displayed one negative signal at $\delta 53.10$ ppm due to - $\mathrm{CH} 2$ - group in the anastrazole, which was not observed in the impurity II. Based on the above spectral data the structure of the impurity II was characterized as 2 , 2'-(5-methyl-1, 3-phenylene) bis (2-methylpropanenitrile) and the molecular formula is $\mathrm{C}_{15} \mathrm{H}_{18} \mathrm{~N}_{2}$.

\section{Structural elucidation of impurity III}

GC-MS spectral data of impurity III was compared with that of anastrozole spectral data. Impurity III exhibited molecular ion $\mathrm{m} / \mathrm{z}, 304(\mathrm{M}+$ ) in GC-MS analysis (Figure 9). This molecular ion is exactly 11 amu more than that of Anastrozole. Interestingly the isotopic abundance due to bromine atom was found to be present in mass spectral data of GC-MS analysis. The first fragment of $\mathrm{m} / \mathrm{z}$ 225(M+) is due to the loss of $\mathrm{Br}^{-}$. This clearly indicated that this impurity having bromine atom.

The ${ }^{1} \mathrm{H}$ NMR spectrum of anastrozole exhibited two separate signals for the protons on the triazole ring, which was not observed in impurity III. The above data can be rationalized in terms of this impurity having the molecular
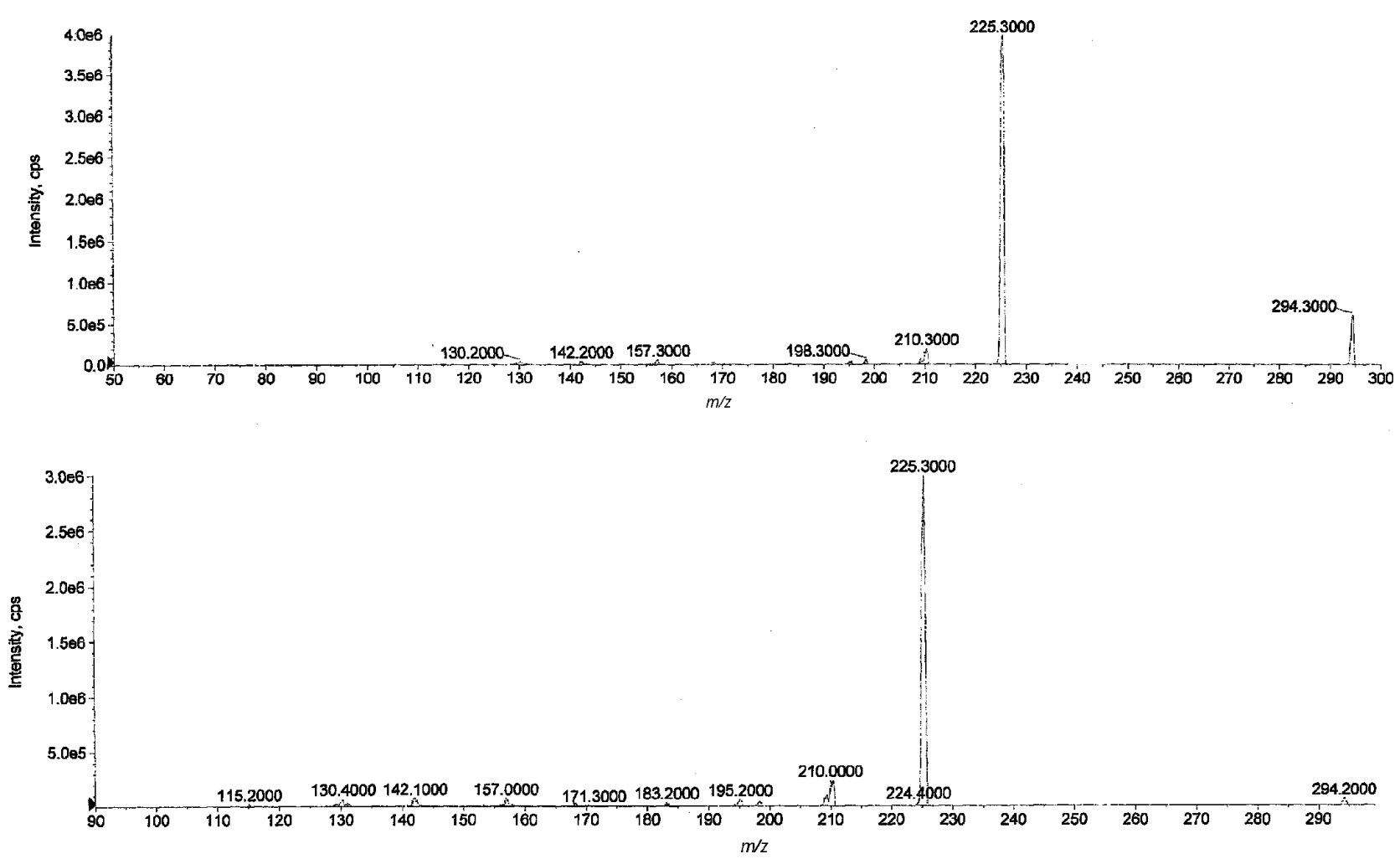

Figure 7. LC-MS/MS spectrum of anastrozole and impurity I. 


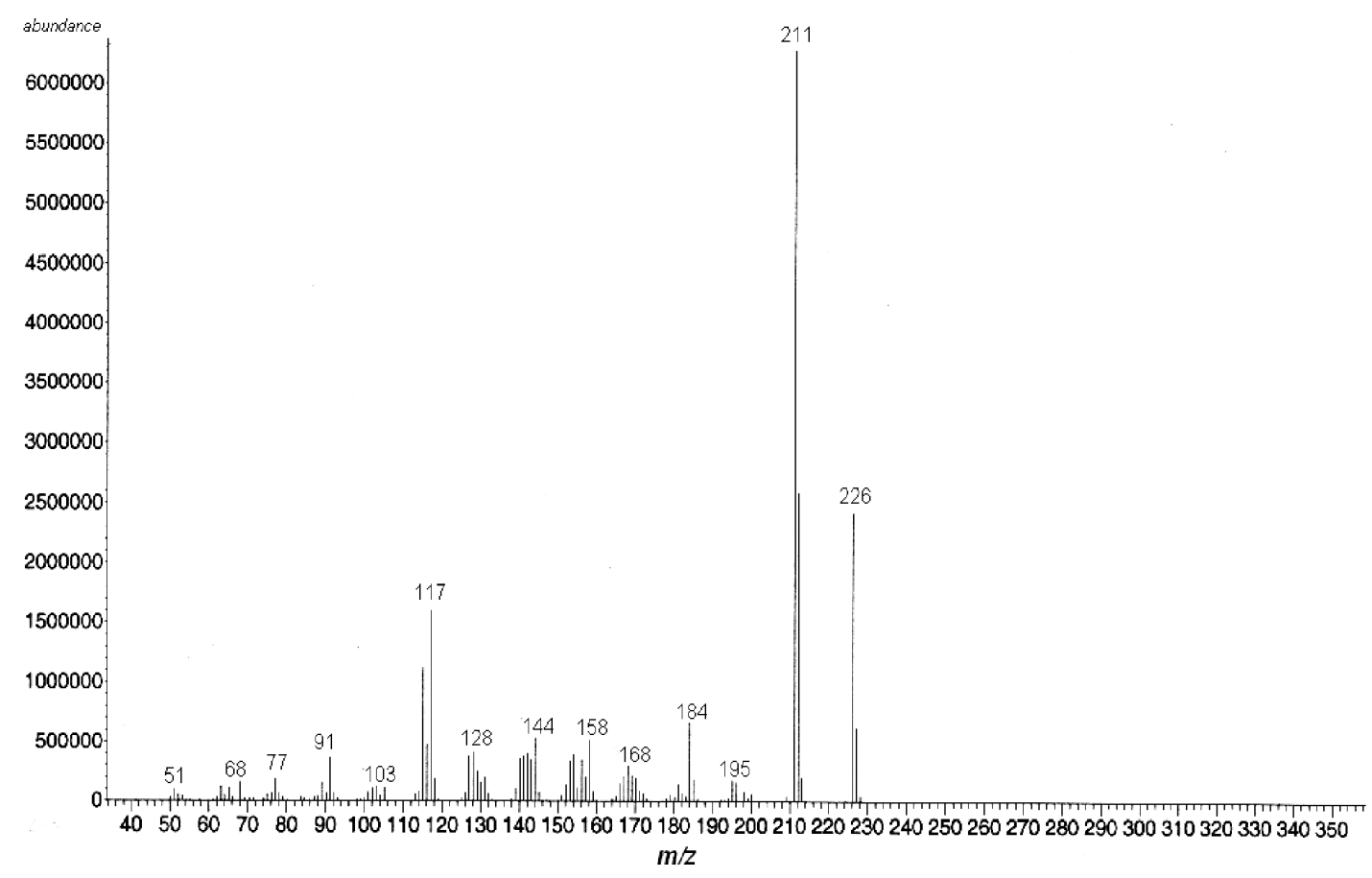

Figure 8. GC-MS spectrum of impurity II.

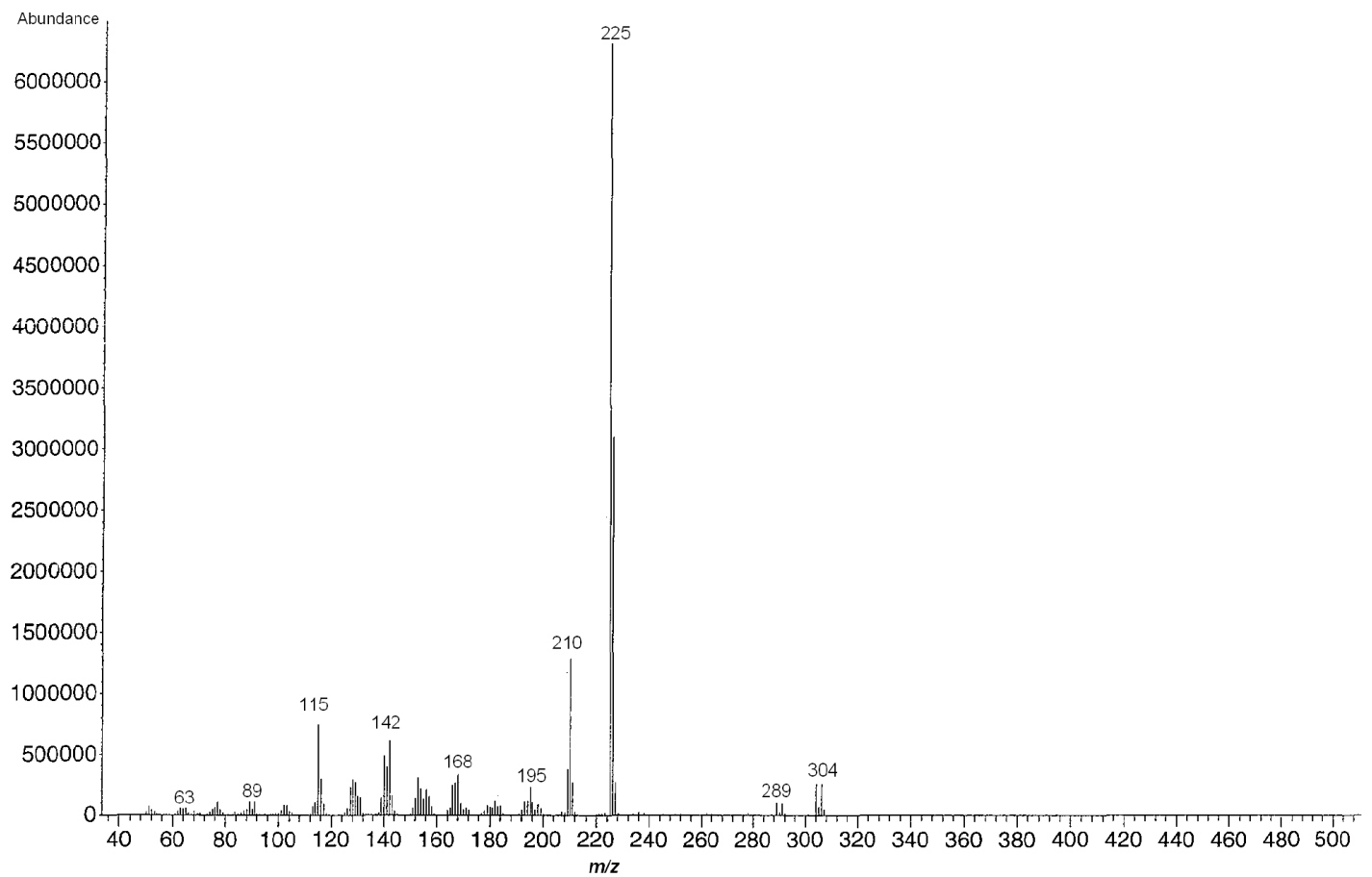

Figure 9. GC-MS spectrum of impurity III.

formula $\mathrm{C}_{15} \mathrm{H}_{17} \mathrm{BrN}_{2}$ and the same was characterized as 2,2'-(5-(bromomethyl)-1,3-phenylene)bis(2-methylpropanenitrile). The major fragments obtained in GC-MS analysis for impurity III is given in Table 1.

\section{Conclusions}

Anastrozole is a potent aromatase inhibitor drug used in the treatment of cancer diseases. The present research 
work describes a HPLC method for detection, separation of three process related impurities from anastrozole and prep-HPLC method for isolation of these impurities from the anastrozole bulk drug. All the three impurities detected were characterized using GC-MS, LC-MS/MS and NMR experimental data.

\section{Acknowledgments}

The authors wish to thank Cipla Ltd, manufacturers of active pharmaceutical ingredients and drug products, Bangalore for giving the sample of anastrozole bulk drug material to carry out the research work.

\section{References}

1. Plourde, P. V.; Dyroff, M.; Dukes, M.; Breast Cancer Res. Treat. 1994, 30, 103.

2. Brodie, A. M. H.; J. Steroid Biochem. Mol. Biol. 1994, 49, 281.

3. Mendes, G. D. ; Hamamoto, D.; Iiha J.; Pereira, A. D. S.; De Nucci,G.; J. Chromatogr., B 2007, 850, 553.

4. Buzdar, A. U.; Roobertson, J. F. R.; Eiermann, W.; Nabholtz, J. M.; Am. Cancer Soc. 2002, 95, 2006

5. Mary Bock, J. H.; Bara, I.; Ledonne, N.; Martz, A.; Dyroff, M; J. Chromatogr, B 1997, 700, 131.

6. Hower, H. L.; Wingo, P. A.; Thum, M. J.; J. Natl. Cancer Inst. 2001, 93, 824 . 